Table 1. Baseline and follow-up metabolic, vascular, and disease activity markers. Values are mean $(\mathrm{SD})$ or mean $(95 \% \mathrm{Cl})$

\begin{tabular}{|c|c|c|c|c|}
\hline Variable & $\begin{array}{c}\text { Baseline } \\
\mathrm{N}=52\end{array}$ & $\begin{array}{c}\text { Change at } \\
\text { Month } 1^{\star} \\
\mathrm{N}=47\end{array}$ & $\begin{array}{c}\text { Change at } \\
\text { Month } 3^{\star} \\
\mathrm{N}=42\end{array}$ & $\begin{array}{c}\text { Change at } \\
\text { Month } 6^{*} \\
\mathrm{~N}=29\end{array}$ \\
\hline Weight (kg) & $\begin{array}{c}95.8 \\
(23.1)\end{array}$ & $\begin{array}{c}-1.1(-1.9,- \\
0.4) \$\end{array}$ & $\begin{array}{c}-1.3(-2.1,- \\
0.5) !\end{array}$ & $\begin{array}{c}-1.9(-2.8,- \\
1.0) \$\end{array}$ \\
\hline BMI $\left(\mathrm{kg} / \mathrm{m}^{2}\right)$ & $34.3(8.7)$ & $\begin{array}{c}-0.4(-0.7,- \\
0.05) \$\end{array}$ & $-0.3(-0.7,0.02)$ & $\begin{array}{c}-0.7(-1.0,- \\
0.3) \$\end{array}$ \\
\hline $\begin{array}{l}\text { Waist circumference } \\
\text { (cm) }\end{array}$ & $\begin{array}{l}107.8 \\
(18.0)\end{array}$ & $-1.6(-3.3,0.2)$ & $-1.0(-2.9,0.8)$ & $-0.9(-3.1,1.2)$ \\
\hline $\mathrm{SBP}(\mathrm{mmHg})^{\S}$ & $\begin{array}{l}132.9 \\
(20.7)\end{array}$ & $-1.5(-5.8,2.8)$ & $-0.6(-5.1,3.8)$ & $-2.1(-7.2,3.0)$ \\
\hline DBP $(\mathrm{mmHg})$ & $\begin{array}{l}77.7 \\
(12.2)\end{array}$ & $2.5(-0.2,5.2)$ & $1.7(-1.1,4.5)$ & $0.5(-2.7,3.7)$ \\
\hline $\mathrm{RHI} \dagger$ & $\begin{array}{c}2.33 \\
(0.55)\end{array}$ & - & $\begin{array}{c}-0.15(-0.38 \\
0.09)\end{array}$ & - \\
\hline 66 Swollen Joint Count & $8.7(6.1)$ & $\begin{array}{c}-3.0(-4.9,- \\
1.1) \$\end{array}$ & $\begin{array}{l}-2.5(-4.5,- \\
0.5) \ddagger\end{array}$ & $\begin{array}{l}-2.7(-4.9,- \\
0.4):\end{array}$ \\
\hline 68 Tender Joint Count & $12.5(9.8)$ & $\begin{array}{c}-2.3(-4.5,- \\
0.1) \$\end{array}$ & $-0.7(-3.0,1.5)$ & $\begin{array}{c}-2.9(-5.5,- \\
0.3)+\end{array}$ \\
\hline DAS28-ESR & $4.3(1.2)$ & $-0.3(-0.6,0.0)$ & $-0.3(-0.6,0.0)$ & $\begin{array}{c}-0.4(-0.7,- \\
0.03) \ddagger\end{array}$ \\
\hline $\begin{array}{l}\text { Patient global } \\
\text { assessment }\end{array}$ & $\begin{array}{c}56.4 \\
(23.8)\end{array}$ & $-7.5(-15.0,0.0)$ & $-7.6(-15.4,0.2)$ & $\begin{array}{c}-9.7(-18.5,- \\
0.8) *\end{array}$ \\
\hline $\begin{array}{l}\text { Physician global } \\
\text { assessment }\end{array}$ & $\begin{array}{c}55.2 \\
(20.2)\end{array}$ & $\begin{array}{c}-18.2(-24.9,- \\
11.5) \ddagger\end{array}$ & $\begin{array}{c}-23.4(-30.4,- \\
16.4) \neq\end{array}$ & $\begin{array}{c}-24.4(-32.5,- \\
16.4) \ddagger\end{array}$ \\
\hline Pain VAS & $\begin{array}{c}52.3 \\
(24.8)\end{array}$ & $-7.8(-15.8,0.2)$ & $\begin{array}{c}-9.0(-17.3,- \\
0.6) \ddagger\end{array}$ & $\begin{array}{c}-12.2(-21.7,- \\
2.8) \$\end{array}$ \\
\hline LEI & $1.6(1.6)$ & $-0.3(-0.6,0.1)$ & $\begin{array}{c}-0.6(-1.0,- \\
0.2) \ddagger\end{array}$ & $\begin{array}{c}-0.6(-1.1,- \\
0.2) \$\end{array}$ \\
\hline PASI & $6.2(8.5)$ & $\begin{array}{c}-2.4(-3.8,- \\
1.0) \neq\end{array}$ & $\begin{array}{c}-2.6(-4.0,- \\
1.2) \ddagger\end{array}$ & $-1.5(-3.1,0.2)$ \\
\hline CRP (mg/dl) & $\begin{array}{c}12.3 \\
(20.8)\end{array}$ & $-3.7(-7.6,0.2)$ & $\begin{array}{c}-5.8(-9.9,- \\
1.8) \ddagger\end{array}$ & $-2.7(-7.2,1.8)$ \\
\hline ESR (mm/hour) & $\begin{array}{c}18.3 \\
(13.7)\end{array}$ & $-0.3(-0.6,0.0)$ & $-0.3(-0.6,0.0)$ & $\begin{array}{c}-0.4(-0.7,- \\
0.03) \$\end{array}$ \\
\hline
\end{tabular}

baseline, $n=26$ at month 3 . $\$ 26 \%(14 / 53)$ on antihypertensives. $\neq p<0.05$.

\section{FRI0432 CLINICAL EXAMINATION AND ULTRASOUND IN THE ASSESSMENT OF PATIENTS WITH PSORIATIC ARTHRITIS WITH AND WITHOUT FIBROMYALGIA}

Alessia Fiorenza ${ }^{1}$, Gianluca Bonitta ${ }^{2}$, Elisabetta Gerratana ${ }^{1}$, Francesca Marino ${ }^{1}$, Pietro Muto ${ }^{1}$, Donatella Sangari ${ }^{1}$, Piercarlo Sarzi-Puttini ${ }^{3}$, Fausto Salaffi ${ }^{4}$, Fabiola Atzeni ${ }^{1} .{ }^{1}$ University of Messina, Rheumatology Unit, Messina, Italy,

${ }^{2}$ University of Milan, Milan, Italy; ${ }^{3}$ L.Sacco University Hospital, Milan, Italy;

${ }^{4}$ University of Jesi, Jesi (Ancona), Italy

Background: Evaluating psoriatic arthritis (PsA)-related enthesitis is diagnostically and therapeutically essential, but may be very complex because of the wide range of signs and symptoms that partly overlap or co-exist with the clinical features of fibromyalgia (FM) $[1,2]$.

Objectives: The primary aim was to compare the prevalence of clinical and ultrasonographic signs of enthesitis in patients with PsA, FM, or both. The secondary aim was to assess the impact of FM on disease activity and clinimetric scores.

Methods: This single-centre, observational cross-sectional study involved 101 consenting patients: 39 with PsA (CASPAR criteria), 23 with FM (2016 criteria), and 39 with both. Standard PsA and FM clinical, laboratory and clinimetric data were recorded. Disease activity in PsA and PsA-FM patients was assessed using BASDAI and ASDAS. The entheses were assessed using LEI and MASES score. All of the patients underwent B mode (grey scale) ultrasonography, the US findings were scored using the GUESS.

Results: The mean age of the patients was 53.6 years, SD \pm 9.47 . Females accounted for $64.1 \%$ of the PsA patients (disease duration 9.13 years, SD \pm 5.9 ), $95.6 \%$ of FM patients (disease duration 5.09 years, SD \pm 3.6 ), and $92.3 \%$ of the patients with PsA-FM (disease duration 7.9 years, SD \pm 5.5). There were no between-group differences in the patients' BMI. None of the FM subjects reported any personal or family history of psoriasis. The mean PASI was $2.3 \pm 3.1$ in the PsA group, and $1.2 \pm 2.45$ in the PsA-FM group. The median BASDAl was significantly higher in PsA-FM vs PsA group (7.7 [IQR 2.1] vs 5.0 [IQR 3.8]; $\mathrm{p}<0.001$ ), as well the median ASDAS score ESR-assessed (3.69 [IQR 1.00 ] vs 2.82 [IQR 1.55]; $\mathrm{p}=0.004$ ), or PCR- assessed (median 3.27 [IQR 1.07] vs 2.66 [IQR 1.26]; $p=0.006$ ). Clinical evidence of enthesopathy was found in $43 \%$ of PsA, $51.3 .8 \%$ of PsA-FM, and $50.8 \%$ of $\mathrm{FM}$, while US entheseal abnormalities were detected in respectively 65\%, $54.6 \%$ and $30 \%$. The median MASES was significantly higher in FM or PSA-FM than in PsA group $(p<0.001)$, no statistically significant difference between FM vs PsA-FM groups (6 [IQR 2] vs 7 [IQR 3]; $\mathrm{p}=0.737$ ). The median LEI was significantly higher in FM or PsA-FM groups $(p<0.001)$, with no statistically significant difference between these two groups(6 [IQR 2] vs 7 [IQR 3]; $p=0.658$ ). The median GUESS was significantly higher in PsA vs FM group (9 [IQR 7.5] vs 3 [IQR 2]; $\mathrm{p}<0.001$ ), and in PsA-FM vs FM group (8 [IQR 4.5] vs 3 [IQR 2]; $p<0.001)$. No statistically significant difference between PsA and PsA-FM group (9 [IQR 7.5] vs 8 [IQR 4.5]; $\mathrm{p}<0.112)$. No statistically significant Spearman correlation coefficient(rho) was found between GUESS and MASES/LEI in any of the groups. There was a correlation between GUESS scores and disease duration in PsA (rho $=0.37 ; \mathrm{p}=0.019,95 \% \mathrm{Cl} 0.10-0.61$ ) or PsA-FM (rho=0.38; $\mathrm{p}=0.016$, $95 \% \mathrm{Cl}$ 0.10-0.61), but not in the FM group, and GUESS scores correlated with $\mathrm{BMI}$ (rho=0.2; $\mathrm{p}=0.05,95 \% \mathrm{Cl} 0.00-0.37$ ) and dyslipidemia (rho $=0.34 ; \mathrm{p}=0.006,95 \% \mathrm{Cl} 0.11-0.58$ ) in all groups.

Conclusion: The use of a clinical examination and clinimetric scores alone may overestimate active enthesitis in FM patients. As US was more frequently positive in patients with PsA and PsA-FM than in those with FM, it may be useful in differentiating pain due to enthesitis from entheseal pain due to FM.

\section{REFERENCES:}

[1] Marchesoni A, et al. The problem in differentiation between psoriaticrelated polyenthesitis and fibromyalgia. Rheumatology. 2018;57:32-40

[2] McGonagle D. Enthesitis: an autoinflammatory lesion linking nail and joint involvement in psoriatic disease.J Eur Acad Dermatol Venereol 2009;23:913

Disclosure of Interests: Alessia Fiorenza : None declared, Gianluca Bonitta Consultant for: Sanofi, Elisabetta Gerratana : None declared, Francesca Marino: None declared, Pietro Muto: None declared, Donatella Sangari: None declared, Piercarlo Sarzi-Puttini Speakers bureau: Novartis, Fausto Salaffi Grant/research support from: Abbvie, Roche, Novartis, BMS, Pfizer, Sanofi, Speakers bureau: Abbvie, Roche, Novartis, Pfizer, Sanofi, BMS, Fabiola Atzeni: None declared DOI: 10.1136/annrheumdis-2019-eular.3764

\section{FRI0433 EFFECTS OF DISEASE MODIFYING DRUGS ON BONE MINERAL DENSITY, FRACTURE INCIDENCE, BACK PAIN AND PHYSICAL ACTIVITY IN PATIENTS WITH PSORIASIS AND PSORIATIC ARTHRITIS}

Desiree Freier ${ }^{1}$, Edgar Wiebe ${ }^{1}$, Kim Zeiner $^{1}$, Robert Biesen ${ }^{1}$, Thomas Buttgereit ${ }^{2}$, Sandra Hermann ${ }^{1}$, Frank Buttgereit ${ }^{1}{ }^{1}$ Charité University Hospital Berlin, Rheumatology and clinical Immunology, Berlin, Germany; ${ }^{2}$ Charité University Hospital Berlin, Dermatology, Venerology and Allergology, Berlin, Germany

Background: Reports on the prevalence of osteoporosis, osteoporotic fractures and risk factors for osteoporosis in patients with psoriasis (PSO) or psoriatic arthritis (PSOA) are scarce, and the published results on this are, at least in part, contradictory. [1] Despite the fact that $\mathrm{IL}-17$ is involved in bone homeostasis under both physiologic and pathologic conditions, there is no detailed knowledge of the direct and indirect impact an IL-17 antagonist like secukinumab (SEC) has on bone mineral density (BMD).

Objectives: Rh-GIOP (ClinicalTrials.gov Identifier NCT02719314) is an ongoing prospective study monitoring glucocorticoid (GC)-induced osteoporosis of rheumatic patients, established in 2015 at the Charite University Hospital. For this analysis, clinical data and bone mineral density data measured by dual x-ray absorptiometry (DXA) of 936 patients with inflammatory rheumatic diseases provided the basis. The main objective of this cross-sectional analysis was to evaluate the prevalence of osteoporosis and the frequency of fractures in patients with PSO or PSOA. Additionally, patients treated with secukinumab were compared to those with methotrexate (MTX) with regard to BMD, fracture incidence, physical activity, and back pain

Methods: We analyzed the initial visit of 103 patients with PSO $(n=31$, $74 \%$ female) or PSOA ( $n=72,64 \%$ female). Descriptive analyses were performed, and values are displayed as means and standard deviations. For subgroup analyses non-parametric tests were used.

Results: The prevalence of osteoporosis in our patient group (mean age: $62 \pm 10$ years; $67 \%$ female; mean disease duration: $17 \pm 13$ years) was $19 \%$. The prevalence of osteopenia was $26 \%, 34 \% \quad(n=35)$ reported peripheral fragility fractures, and $11 \% \quad(n=11)$ had vertebral fractures in history. Regular physical activity was reported by $41 \%(n=42)$, while $53 \%$ $(n=55)$ suffered from movement restrictions. Back pain was present in $68 \%(n=70)$ of patients with a mean numeric rating scale of 5 (NRS; 0 - 
10). SEC was used by $18 \%(n=19)$, and MTX by $42 \%(n=43,25 \%$ sc, $13 \%$ oral, $4 \%$ unknown), respectively. Eight percent had a combination therapy of MTX and SEC. Twenty-seven percent used GC and/or other biologics/conventional disease modifying antirheumatic drugs (DMARDs). Mean glucocorticoid cumulative dose (GCCD) was 12.8 $\pm 22.0 \mathrm{~g}$. Patients with SEC showed a significantly longer disease duration (median: 24 years vs. 13 years) compared to MTX, but showed no other differences in baseline-characteristics or risk factors. T-Scores of both femora were significantly higher in the MTX versus the SEC group. We could not find significant differences between these groups with regard to physical activity, back pain, movement restriction, fracture rates or GCCD. Twenty-five percent of the MTX users and $27 \%$ of the patients in the SEC group additionally had GC while; in contrast to no patient in the combination group.

Conclusion: The prevalence of osteoporosis in patients with PSO or PSOA was found to be as high as in the normal population. However, there was a high frequency of peripheral fragility, but not vertebral fractures. Patients with PSO or PSOA patients treated with SEC had a longer disease duration and lower hip BMD, but showed no differences in back pain, physical activity or movement restrictions compared to MTX users.

Funding: Rh-GIOP is supported by a joint funding of Amgen, BMS, Celgene, Generic Assays, GSK, Hexal, Horizon, Lilly, medac, Mundipharma, Novartis, Pfizer, Roche, and Sanofi.

\section{REFERENCES:}

[1] Frediani, B., et al., Bone mineral density in patients with psoriatic arthritis. J Rheumatol, 2001. 28(1): p. 138-43.

Disclosure of Interests: Desiree Freier: None declared, Edgar Wiebe Grant/research support from: Rh-GIOP is supported by a joint funding of Amgen, BMS, Celgene, Generic Assays, Chugai, Hexal AG, Horizon, Lilly, medac, Mundipharma, Novartis, Pfizer, Roche, and Sanofi., Kim Zeiner: None declared, Robert Biesen: None declared, Thomas Buttgereit: None declared, Sandra Hermann: None declared, Frank Buttgereit: None declared

DOI: 10.1136/annrheumdis-2019-eular.4792

\section{FRI0434 $\quad$ THE RELATIONSHIP BETWEEN SYMPTOMS OF AUTONOMIC DYSFUNCTION AND CARDIOVASCULAR INVOLVEMENT IN PSORIATIC ARTHRITIS}

Halise Hande Gezer, Didem Erdem, Mehmet Tuncay Duruöz. Marmara University School of Medicine, Department of Physical Medicine and Rehabilitation, Rheumatology Division, Istanbul, Turkey

Background: The incidence of cardiovascular disease (CVD), diabetes mellitus, metabolic syndrome and subclinical atherosclerosis is markedly increased in patients with psoriatic arthritis (PsA). The autonomic nervous system is the visceral nervous system of the body consisting of two parts; sympathetic and parasympathetic. Patients with PsA have predominantly parasympathetic involvement autonomic nervous system.

Objectives: The aim of this study was to evaluate the symptoms of autonomic dysfunction and their relationship with cardiovascular involvement and other clinic parameters in patients with PsA.

Methods: The study included patients diagnosed with PsA according to the CASPAR criteria. For evaluation of cardiovascular involvement, body mass index (BMI), abdominal obesity, hypertension (HT), diabetes mellitus (DM), hyperlipidemia $(\mathrm{HL})$, metabolic syndrome, fasting glucose levels, lipid levels, systolic and diastolic blood pressures (SBP-DBP) were assessed. DAPSA (Disease Activity in Psoriatic Arthritis), BASDAI (Bath Ankylosing Spondylitis Disease Activity Index), Leeds enthesitis index, Psoriasis Area Severity Index (PASI), Psoriatic Arthritis Quality of Life (PsAQoL) and Health Assessment Questionnaire (HAQ) were used to assess patients clinical situations. The Composite Autonomic Symptom Score (COMPASS-31) (range:0-100) consisting of 6 subdivisions including orthostatic, vasomotor, secretomotor, gastrointestinal (GIS), bladder and pupillomotor was used for the symptoms of autonomic dysfunction. The Mann-Whitney U-test, student's t-test and Spearman's correlation coefficient were used for statistical analysis. $\mathrm{P}<0.05$ was considered statistically significant.

Results: A total of 64 subjects (43 female, 21 male) with a mean of age 49 years (SD:12.3) and disease duration of 59 months (SD:71.3) were recruited into the study. The patients had HT (23.4\%), DM (17.2\%), abdominal obesity $(62.5 \%)$, metabolic syndrome $(45.3 \%)$ and dyslipidemia $(42.2 \%)$. The mean total COMPASS-31 score was 19.7 (SD:8.3). There was no significant difference in COMPASS-31 scores in patients with or without HT, DM, dyslipidemia. Bladder scores were significantly higher in patients with abdominal obesity and metabolic syndrome $(p<0.05)$. GIS and pupillomotor scores were significantly higher in patients with enthesis $(p<0.05)$. Significant correlations were found between: LDL and bladder $(r=0.392)$ scores; enthesis and GIS $(r=0.303)$, pupillomotor $(r=0.365)$ scores; DAPSA and total COMPASS-31 $(r=0.310)$, secretomotor $(r=0.359)$ scores; BASDAI and total COMPASS-31 ( $r=0.483)$, GIS $(r=0.327)$, secreto motor $(r=0.309)$, pupillomotor $(r=0.302)$ scores; fatigue and total COM PASS-31 ( $r=0.503)$, GIS $(r=0.377)$, pupillomotor $(r=0.302)$ scores; HAQ and total COMPASS-31 $(r=0.476)$, orthostatic $(r=0.388)$, bladder $(r=0.371)$ scores; PsAQoL and total COMPASS-31 ( $r=0.601)$, orthostatic $(r=0.549)$, secretomotor $(r=0.414)$, pupillomotor $(r=0.380)$ scores.

Conclusion: The total score of COMPASS-31 and its subdivisions were high in PsA patients as compared with literature data on healthy subjects. The symptoms of autonomic dysfunction were increased in PsA patients. Disease activity, functional impairment, fatigue, LDL and quality of life are associated with autonomic dysfunction. Autonomic symptoms improve with disease control.

\section{REFERENCES:}

[1] Sletten, D.M., et al., COMPASS 31: a refined and abbreviated Composite Autonomic Symptom Score. Mayo Clinic Proceedings, 2012. 87(12): p. 1196-1201

[2] Syngle, A., et al., Autonomic dysfunction in psoriatic arthritis. Clin Rheumatol, 2013. 32(7): p. 1059-64.

Disclosure of Interests: Halise Hande Gezer: None declared, Didem Erdem: None declared, Mehmet Tuncay Duruöz Grant/research support from: Abvie, Speakers bureau: Novartis, AMGEN, Abdi İbrahim, İlko DOI: 10.1136/annrheumdis-2019-eular.6282

\section{FRI0435 DISEASE CHARACTERISTICS ON EFFICACY OF AN ORAL, SELECTIVE TYK2 INHIBITOR, BMS-986165, IN PATIENTS WITH PLAQUE PSORIASIS IN A PHASE 2 TRIAL}

Kenneth Gordon $^{1}$, Kim Papp ${ }^{2}$, Melinda Gooderham ${ }^{3}$, Diamant Thaçi ${ }^{4}$,

Peter Foley ${ }^{5}$, Akimichi Morita ${ }^{6}$, Sudeep Kundu ${ }^{7}$, Renata Kisa ${ }^{7}$, Andrew Napoli ${ }^{7}$, Subhashis Banerjee ${ }^{7}$. ${ }^{1}$ Medical College of Wisconsin, Milwaukee, United States of America; ${ }^{2} \mathrm{~K}$ Papp Clinical Research and Probity Medical Research, Waterloo, Canada; ${ }^{3}$ SKiN Centre for Dermatology, Queen's University and Probity Medical Research, Peterborough, Canada; ${ }^{4}$ University of Lübeck, Lübeck, Germany; ${ }^{5}$ The University of Melbourne, St Vincent's Hospital Melbourne and Probity Medical Research, Skin and Cancer Foundation Inc, Melbourne, Australia; ${ }^{6}$ Nagoya City University Graduate School of Medical Sciences, Nagoya, Japan; ${ }^{7}$ Bristol-Myers Squibb, Princeton, United States of America

Background: BMS-986165 is an oral, selective inhibitor of tyrosine kinase 2 (TYK2), an enzyme that activates signal transducer and activator of transcription (STAT)-dependent cytokine signalling pathways involved in the pathophysiology of psoriasis (PsO). In a 12-week, Phase 2 trial of BMS-986165 in patients with moderate to severe plaque $\mathrm{PsO}$, including those with baseline (BL) musculoskeletal symptoms, Psoriasis Area and Severity Index (PASI) 75 responses (primary endpoint) were highest at doses $\geq 3 \mathrm{mg}$ twice daily (BID; $67-75 \%)$ vs placebo $(7 \% ; P<0.001)$, with a favourable safety profile.

Objectives: To evaluate the influence of $\mathrm{BL}$ demographics (weight, body mass index, age) and disease characteristics (age of onset, presence of musculoskeletal symptoms, disease duration, previous biologic use, PASI score, static Physician Global Assessment [sPGA] score, Dermatology Life Quality Index [DLQI] score) on Week 12 efficacy for the 3 most effective doses of BMS-986165 (3 mg BID, $6 \mathrm{mg} \mathrm{BID}$, and $12 \mathrm{mg}$ once daily [QD]) in the trial.

Methods: Adults with moderate to severe plaque PsO (body surface area [BSA] $\geq 10 \%$, PASI score $\geq 12$, sPGA score $\geq 3$ ) were randomised equally to 1 of 5 oral doses of BMS-986165 (3 mg every other day, $3 \mathrm{mg}$ QD, $3 \mathrm{mg}$ BID, $6 \mathrm{mg} \mathrm{BID,} 12 \mathrm{mg} \mathrm{QD)}$ ) or placebo for 12 weeks.

Results: A total of 267 patients were treated; subgroup analyses based on BL characteristics are reported for patients treated with the most effective doses of BMS-986165 ( $\geq 3 \mathrm{mg}$ BID; $n=134$ ). BMS986165 showed no meaningful differences in efficacy among almost all of the 3 subgroups, including age of onset, presence of musculoskeletal symptoms, and disease duration (Table), with some variability across subgroups. Small patient numbers may underlie observed fluctuations in results. Similar consistency in responses was seen regardless of $B L$ age (18-<45 years, $n=66$; $\geq 45$ years, $n=68$ ), weight 